CLINICAL STUDY

\title{
GH replacement in hypopituitarism improves lipid profile and quality of life independently of changes in obesity variables
}

\author{
Pascale Abrams $^{1,2}$, Hugo Boquete ${ }^{3}$, Hugo Fideleff ${ }^{3}$, Ulla Feldt-Rasmussen ${ }^{4}$, Peter J Jönsson ${ }^{5}$, \\ Maria Koltowska-Häggström ${ }^{5,6}$, Patrick Wilton ${ }^{7}$ and Roger Abs ${ }^{1}$ \\ ${ }^{1}$ Department of Endocrinology, University of Antwerp, 2560 Antwerp, Belgium, ${ }^{2}$ Department of Endocrinology, St Augustine and St Vincent Hospital, \\ 2610 Antwerp, Belgium, ${ }^{3}$ Department of Endocrinology, Hospital T Alvarez, Buenos Aires, Argentina, ${ }^{4}$ Department of Endocrinology, National University \\ Hospital, Copenhagen, Denmark, ${ }^{5}$ Department of Endocrinology, KIMS Medical Outcomes, Pfizer Endocrine Care, Sollentuna, Sweden, ${ }^{6}$ Department of \\ Pharmacy, Uppsala University, Uppsala, Sweden and ${ }^{7}$ KIGS-KIMS-ACROSTUDY Medical Outcomes, Pfizer Endocrine Care, New York, New York, USA
}

(Correspondence should be addressed to P Abrams who is now at Universiteitsplein, B-2610 Wilrijk, Belgium; Email: pascale.abrams@belgacom.net)

\begin{abstract}
Objective: GH deficiency (GHD) in adults is characterized by elevated body mass index (BMI), increased waist girth (WG) and increased fat mass (FM). Information about how these indicators of obesity affect the lipid profile and quality of life (QoL) of GHD subjects is scarce. It is also unclear how changes in these indicators brought about by GH replacement influence lipids and QoL.

Design and methods: Adult GHD subjects from the Pfizer International Metabolic Database were grouped according to BMI ( $n=291$ with BMI $<25 \mathrm{~kg} / \mathrm{m}^{2}, n=372$ with BMI $25-30 \mathrm{~kg} / \mathrm{m}^{2}, n=279$ with BMI $\left.>30 \mathrm{~kg} / \mathrm{m}^{2}\right)$, WG $(n=508$ with normal WG, $n=434$ with increased WG) and FM $(n=357)$ and according to changes in these variables after 1 year of GH replacement. Serum IGF-I concentrations, lipid concentrations and QoL using the QoL Assessment of GHD in Adults questionnaire were assessed at baseline and after 1 year of treatment.

Results: At baseline, total and low-density lipoprotein (LDL) cholesterol were similarly elevated in the BMI and WG groups, but high-density lipoprotein (HDL) cholesterol decreased and triglycerides increased with increasing BMI and WG. QoL was progressively poorer with increasing BMI and WG. After 1 year of GH replacement, total and LDL cholesterol and QoL improved in all BMI, WG and FM groups.

Conclusions: Variables of obesity adversely affect the already unfavourable lipid profile in GHD subjects by decreasing HDL cholesterol, but do not counteract the positive effect of GH replacement on LDL cholesterol. Similarly, QoL is influenced by obesity, but responds equally well to GH treatment independent of BMI, WG and FM.
\end{abstract}

European Journal of Endocrinology 159 825-832

\section{Introduction}

The adverse lipid profile in subjects with growth hormone (GH) deficiency (GHD) and the mortality associated with this altered lipid profile (1-3) is the risk factor that has probably attracted most attention (4-6), although lipid abnormalities have not been demonstrated in all studies (7). GHD is also associated with conditions related to hyperlipidaemia, such as increased body weight (8-10), abnormal body composition (11, 12 ), and fat accumulation with increased waist-hip ratio (6). It has been convincingly demonstrated that $\mathrm{GH}$ replacement induces favourable changes in these different cardiovascular risk factors $(6,13-15)$. Another major characteristic of GHD is impaired quality of life (QoL), demonstrated by general surveys and confirmed by disease-related questionnaires such as the QoL Assessment of GHD in Adults (QoL-AGHDA) (16) and Questions on Life Satisfaction-Hypopituitarism
(17). These QoL deficits have been shown to be reversed by GH replacement $(18,19)$.

Reduction in body fat in overweight and obese subjects without GHD improves lipid profile $(20,21)$ and QoL (22) per se. A correlation between reduction in cholesterol and decrease in fat mass (FM) during $\mathrm{GH}$ treatment has similarly been proposed $(23,24)$. However, there is little detailed information regarding the relationship between key indicators of obesity and the lipid profile and QoL of subjects with GHD. Moreover, no data are available on whether changes in these variables during GH replacement have any impact on blood lipids or QoL.

The present study sought to evaluate the relationship between GHD and obesity, blood lipids and QoL in subjects with GHD. Several clinical parameters were used to characterize and quantitate the degree of obesity, including body mass index (BMI), waist girth (WG) and FM. The effect of GH replacement on obesity, 
blood lipids and QoL was assessed by evaluating changes in these parameters in response to $\mathrm{GH}$ treatment.

\section{Subjects and methods}

\section{Subjects}

The data in this analysis were retrieved from KIMS (Pfizer International Metabolic Database, Pfizer, NY, USA), the largest database for monitoring the safety and outcomes of long-term GH replacement in adults with GHD. Subjects were included if they had GHD (defined as a GH peak response $<3 \mu \mathrm{g} / \mathrm{l}$ after provocation testing with insulin or arginine, or with glucagon in those with multiple hormonal deficits) and had received no $\mathrm{GH}$ therapy for at least 6 months before entry. Subjects with diabetes mellitus and those taking lipid-lowering drugs or drugs that enhance weight loss were excluded.

All subjects were studied in a longitudinal manner when analysed for the effect of GH replacement therapy. Data from the same 942 subjects (mean age $44.7 \pm$ 14.6 years; $49.9 \%$ male, $78.3 \%$ adult-onset, BMI $28.0 \pm 5.7 \mathrm{~kg} / \mathrm{m}^{2}$ ) were analysed for the BMI and the WG studies and from this group 357 subjects could be retrieved for the FM studies.

The main causes of GHD were pituitary adenoma (55\%), idiopathic hypopituitarism (10\%), craniopharyngioma $(10 \%)$, other pituitary and hypothalamic tumours $(6 \%)$ and tumours distant from the hypothalamic-pituitary region (5\%). Isolated GHD was present in $10 \%$ of subjects and panhypopituitarism with diabetes insipidus in $18 \%$. Subjects with additional deficiencies apart from GH were accordingly substituted.

To study the influence of BMI, the subjects were divided into three groups according to their weight:

- the 'BMI $<25$ ' group $(n=291 ; 30.9 \%)$ with a BMI $<25 \mathrm{~kg} / \mathrm{m}^{2}$

- the 'BMI $=25-30$ ' group $(n=372 ; 39.5 \%)$ with a BMI between 25 and $30 \mathrm{~kg} / \mathrm{m}^{2}$

- the 'BMI $>30$ ' group $(n=279 ; 29.6 \%)$ with a BMI $>30 \mathrm{~kg} / \mathrm{m}^{2}$.

To study the influence of WG, the subjects were divided into two groups according to their waist circumference:

- the 'WG-normal' group ( $n=508 ; 53.9 \%)$, comprising males with a waist circumference $<102 \mathrm{~cm}$ and females with a waist circumference $<88 \mathrm{~cm}$

- the 'WG-abnormal' group $(n=434 ; 46.1 \%)$, comprising males with a waist circumference $\geq 102 \mathrm{~cm}$ and females with a waist circumference $\geq 88 \mathrm{~cm}$.

The impact of FM was studied in all patients for whom information was available. There was an important overlap and thus consistency between the BMI and WG groups, as $93 \%$ of subjects from the BMI $<25$ group belonged to the WG-normal group and $94 \%$ of subjects from the BMI > 30 group to the WG-abnormal group.

To study the influence of changes in each of the three obesity variables, the subjects were regrouped according to the magnitude of change:

- body mass: the 'BMI $\downarrow$ ' group, comprising subjects with a decrease of more than $1 \mathrm{~kg} / \mathrm{m}^{2}(n=192$; $20.4 \%$ ); the 'BMI =' group, comprising subjects with changes between -1 and $+1 \mathrm{~kg} / \mathrm{m}^{2}(n=556$; $59.0 \%$ ); the 'BMI $\uparrow$ ' group, comprising subjects with an increase of more than $1 \mathrm{~kg} / \mathrm{m}^{2}(n=194$; $20.6 \%)$

- WG: the 'WG $\downarrow$ ' group, comprising subjects with a decrease of more than $2 \mathrm{~cm}(n=363 ; 38.5 \%)$; the ' $W G=$ ' group, comprising subjects with changes between 0 and $-2 \mathrm{~cm}(n=274 ; 29.1 \%)$; the 'WG $\uparrow$ ' group, comprising subjects with any increase in WG $(n=305 ; 32.4 \%)$;

- FM: the 'FM $\downarrow$ ' group, comprising subjects with a decrease of more than $2 \mathrm{~kg}(n=116 ; 32.5 \%)$; the 'FM =' group, comprising subjects with changes between 0 and $-2 \mathrm{~kg}(n=103 ; 28.9 \%)$; the 'FM $\uparrow$ ' group, comprising subjects with any increase in FM $(n=138 ; 38.6 \%)$.

\section{Methods}

Background information including gender, onset of GHD, history of prior GH therapy, age at aetiological diagnosis, age at diagnosis of GHD and age at inclusion into KIMS for each of these groups was added to the KIMS database according to the study guidelines on the KIMS case report forms. It is a condition of entry into KIMS that each centre obtains approval from their local ethics committee and that patients give informed consent, either verbally or in writing, depending on the local regulatory requirements. The study was performed in accordance with The Declaration of Helsinki (25).

Measurement of insulin-like growth factor I (IGF-I) was conducted in a single central laboratory. Until 2002, it was performed by RIA after acid-ethanol precipitation of the IGF-binding proteins (Nichols Institute Diagnostics, San Juan Capistrano, CA, USA). Thereafter, a chemiluminescence immunoassay (Nichols Advantage System) was introduced. Longterm reproducibility, measured over more than 1 year, showed a coefficient of variation of $<9 \%$ in the concentration range $130-850 \mu \mathrm{g} / \mathrm{l}$. The assay detection limit was $30 \mu \mathrm{g} / \mathrm{l}$. The reference range in the IGF-I assay was adjusted for gender and age. FM was calculated by bioelectrical impedance analysis (BIA). Determinations of serum total cholesterol, high-density lipoprotein (HDL) cholesterol and triglycerides were performed centrally and concentrations of low-density lipoprotein 
(LDL) cholesterol were calculated using Friedewald's formula (26). Results are expressed as mmol/l. The ratio of total to HDL-cholesterol was also calculated. QoL was measured using the QoL-AGHDA questionnaire (16); higher scores denote poorer QoL (to a maximum of 25).

\section{Statistical analysis}

Data analyses were performed using SAS (Statistical Analysis System, SAS Institute, Cary, NC, USA). Data are presented as means \pm s.D., unless otherwise specified.

The significance of effects between groups was assessed with Student's unpaired $t$-test for normally distributed data and otherwise by Wilcoxon's rank-sum test. Significance was accepted with $P$ values of $<0.05$.

Multiple linear regression analysis was performed for lipids and QoL-AGHDA to take into account the effects of age, BMI, WG and FM at baseline when comparing changes over time.

\section{Results}

Background data are shown in Table 1. The gender distribution was almost equal in the FM group, but there were more females in the BMI $<25$ group and BMI $>30$ groups and in the WG-abnormal group. The proportions of subjects with childhood onset were higher in the BMI $<25$ and WG-normal groups, paralleling the mean ages at aetiological diagnosis and entry into KIMS. Overall, the mean age for both factors was the lowest in the BMI $<25$ group and lower for the WG-normal group than for the WG-abnormal group. As intended, the BMI and WG groups were significantly different from each other for the three variables we used as indicators of obesity. The data from the FM group mirrored the data from the complete cohort of 942 subjects for each variable (data not shown). Table 1 also shows a significantly lower IGF-I concentration in the BMI $<25$ group. The daily GH dose was higher in the BMI $<25$ group and was associated with a greater increase in IGF-I after 1 year of GH replacement therapy.

Baseline data are shown in Table 2. There were no differences in total and LDL cholesterol between the three BMI groups. On the other hand, increased BMI was accompanied by a significantly progressive decrease in HDL cholesterol and a significant increase in triglycerides. As a result, the total/HDL-cholesterol ratio was lowest in the BMI $<25$ group and was the highest in the BMI $>30$ group. QoL overall was poor and significantly worse in the BMI $>30$ group than in the other two BMI groups. Findings were similar for the two WG groups. WG did not influence total and LDL cholesterol, but the total/HDLcholesterol ratio was higher in the WG-abnormal group due to lower HDL cholesterol. QoL was significantly poorer in the WG-abnormal group. The lipid and QoL data in the FM group again reflected the data from the whole cohort.

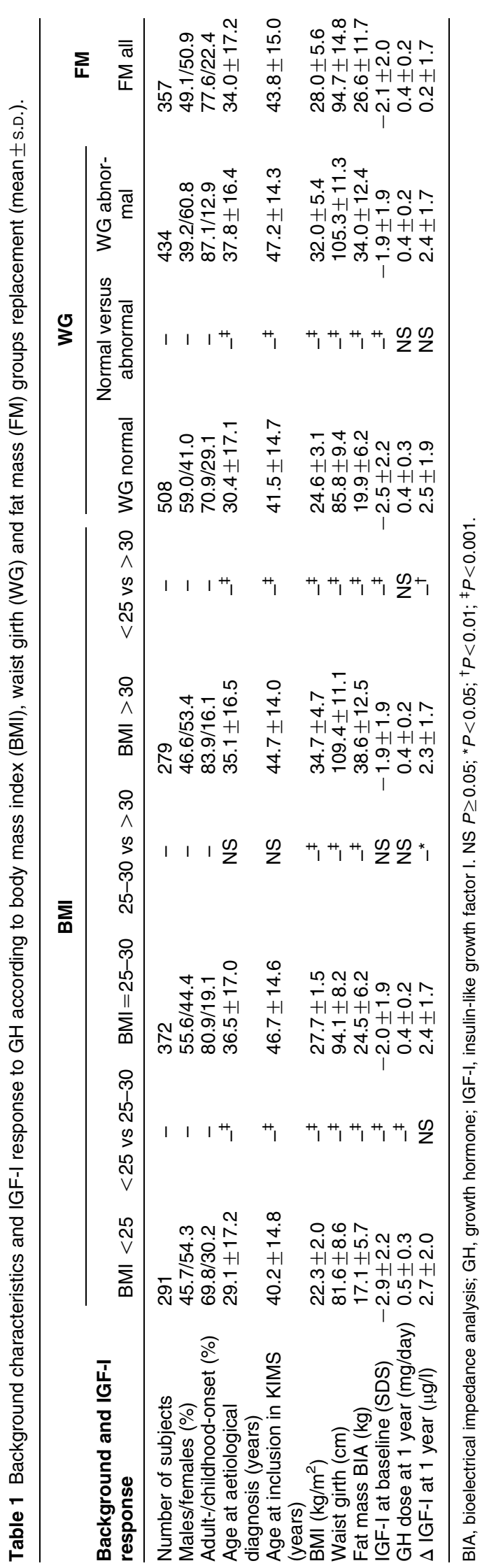

www.eje-online.org 


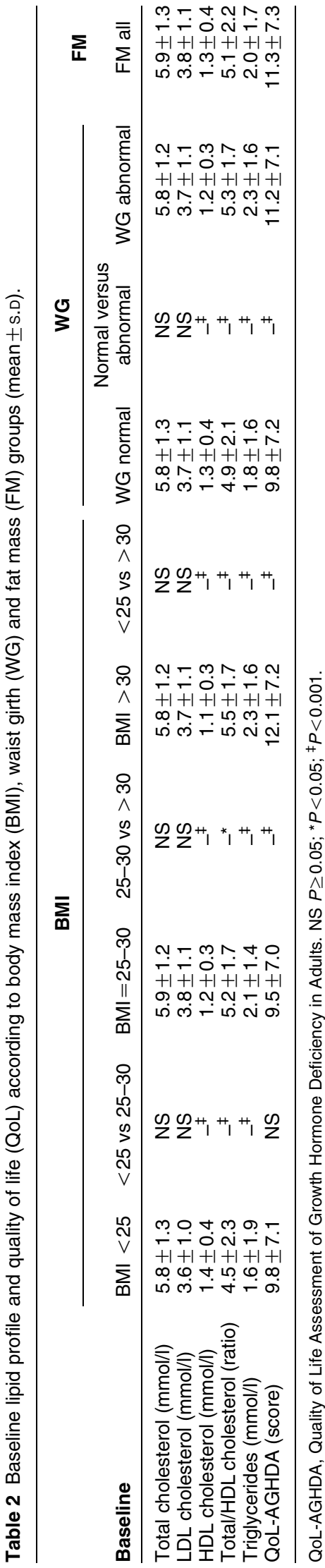

One year of GH replacement had no overall effect on BMI for the whole cohort of 942 subjects $(0.0 \pm$ $\left.1.5 \mathrm{~kg} / \mathrm{m}^{2}, P \geq 0.05\right)$ or for the BMI $=25-30$ group $\left(0.0 \pm 1.4 \mathrm{~kg} / \mathrm{m}^{2}, P \geq 0.05\right)$, while a small but significant increase in the BMI $<25$ group $\left(+0.2 \pm 1.2 \mathrm{~kg} / \mathrm{m}^{2}\right.$, $P<0.01)$ and a small but significant decrease in the BMI $>30$ group $\left(-0.3 \pm 1.9 \mathrm{~kg} / \mathrm{m}^{2}, P<0.05\right)$ were seen. The decrease in $W G$ was significant for the whole cohort $(-1.7 \pm 5.4 \mathrm{~cm}, P<0.001)$, the BMI $<25$ group $(-1.1 \pm 5.0 \mathrm{~cm}, P<0.001)$, the $\mathrm{BMI}=$ 25-30 group $(-1.6 \pm 5.2 \mathrm{~cm}, P<0.001)$ and the BMI $>30$ group $(-2.5 \pm 6.1 \mathrm{~cm}, P<0.001)$. FM decreased in the whole cohort $(-1.3 \pm 4.5 \mathrm{~kg}, P<0.001)$, the BMI $<25$ group $(-0.7 \pm 4.1 \mathrm{~kg}, P<0.05)$, the $\mathrm{BMI}=25-30$ group $(-1.8 \pm 4.2 \mathrm{~kg}, P<0.001)$ and the BMI $>30$ group $(-1.3 \pm 5.2 \mathrm{~kg}, P<0.05)$. Subjects with either a normal or an abnormal WG displayed a similar pattern. The changes in BMI were small and non-significant in the WG-normal and WG-abnormal groups $\left(+0.1 \pm 1.3 \mathrm{~kg} / \mathrm{m}^{2} ; P \geq 0.05\right.$ and $-0.2 \pm 1.8 \mathrm{~kg} / \mathrm{m}^{2}$; $P \geq 0.05$ respectively). The changes in $\mathrm{WG}$ were also highly significant in the WG-normal and WG-abnormal groups $\quad(-1.0 \pm 4.5 \mathrm{~cm} ; \quad P<0.001$ and $-2.6 \pm$ $5.9 \mathrm{~cm} ; P<0.001$ respectively). The changes in $\mathrm{FM}$ were also highly significant in the WG-normal group $(-1.4 \pm 4.1 \mathrm{~kg} ; P<0.001)$. The change was smaller but still significant in the WG-abnormal group $(-1.2 \pm$ $4.9 \mathrm{~kg} ; P<0.01)$.

Table 3 shows the changes in lipids and QoL induced by GH replacement for the different BMI, WG and FM groups. A similar effect on the lipid profile was seen in each group, with a significant decrease in total and LDL cholesterol, no or minimal changes in HDL cholesterol and a minimal although significant increase in triglycerides. The reduction in cholesterol was more pronounced in the BMI $>30$ group. The total/HDL cholesterol ratio fell in each group. The improvement in QoL was significant and comparable for the three BMI groups and the two WG groups. The changes in the FM group were similar to the changes in the total cohort.

Figure 1 depicts the effect of GH replacement on the lipid profile depending on the changes in obesity variable. Figure 1a shows the favourable effect upon total cholesterol, LDL cholesterol and total/HDL cholesterol ratio, which was independent of the change in BMI. Total cholesterol decreased by $-0.5 \pm 1.0 \mathrm{mmol} / \mathrm{l}$ in the BMI $\downarrow$ group $(P<0.001)$, by $-0.3 \pm 1.0 \mathrm{mmol} / \mathrm{l}$ in the $\mathrm{BMI}=$ group $(P<0.001)$, and by $-0.2 \pm$ $0.9 \mathrm{mmol} / \mathrm{l}$ in the BMI $\uparrow$ group $(P<0.01)$, while the ratios decreased by $-0.6 \pm 1.1(P<0.001),-0.3 \pm 1.8$ $(P<0.001),-0.1 \pm 1.3(P \geq 0.05)$ respectively. Multivariate analysis did not disclose a significant difference between the three BMI groups. The change in HDL cholesterol was not significant and the increase in triglycerides was limited although significant $(P<0.001$ for all groups). Figure $1 \mathrm{~b}$ shows that the decrease in total cholesterol, LDL cholesterol and total/HDL ratio was also independent of changes in WG. Total 
(a)

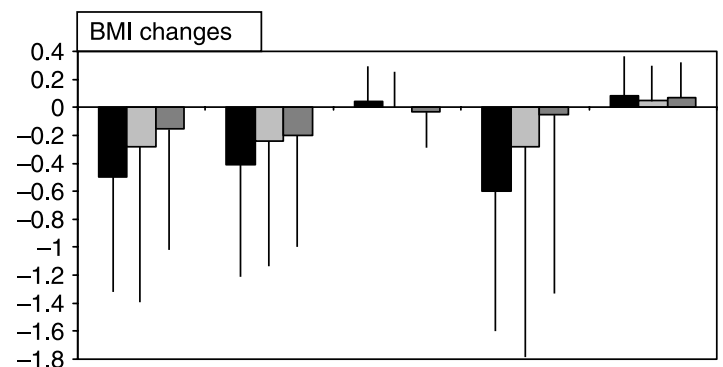

(b)

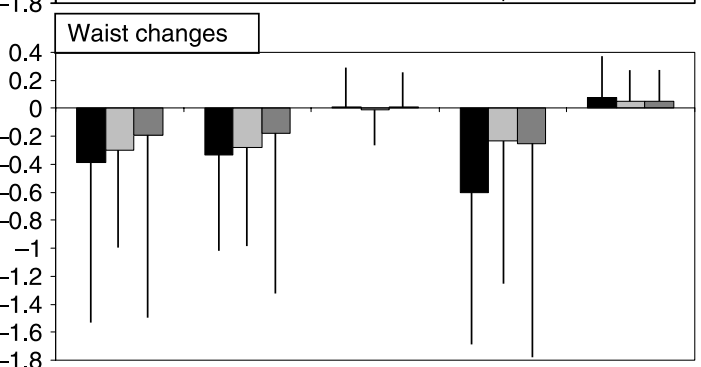

(c)

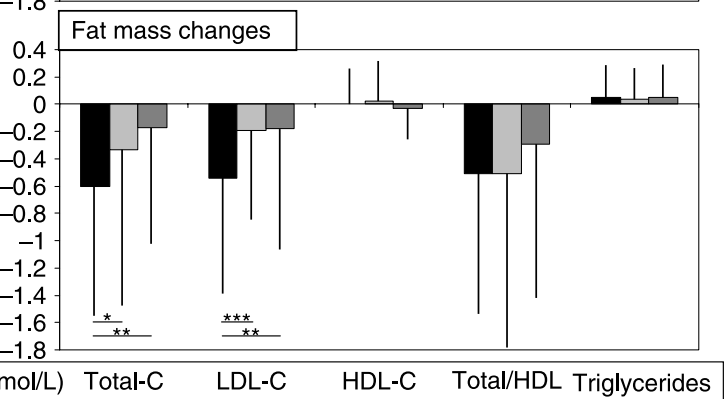

Figure 1 Changes in total cholesterol, LDL cholesterol, HDL cholesterol, total cholesterol/HDL cholesterol ratio, triglycerides in subjects with growth hormone deficiency (GHD) classified according to changes in (a) body mass index (BMI), (b) waist girth (WG), and (c) fat mass (FM) after 1 year of growth hormone replacement. Values are means \pm s.D. ${ }^{\star} P<0.05 ;{ }^{* \star} P<0.01 ;{ }^{\star \star \star} P<0.001$.

cholesterol decreased by $-0.4 \pm 1.1 \mathrm{mmol} / \mathrm{l}$ in the $W G \downarrow$ group $(P<0.001)$, by $-0.3 \pm 0.8 \mathrm{mmol} / \mathrm{l}$ in the $W G=$ group $(P<0.001)$, and by $-0.2 \pm 1.3 \mathrm{mmol} / \mathrm{l}$ in the WG $\uparrow$ group $(P<0.01)$, while the ratio decreased by $-0.6 \pm 1.1 \quad(P<0.001), \quad-0.2 \pm 1.0 \quad(P<0.001)$, $-0.3 \pm 1.8 \quad(P<0.01)$ respectively. Multivariate analysis did not reveal differences between the three WG groups. The change in HDL cholesterol was not significant and the increase in triglycerides was limited although significant $(P<0.001$ for all groups). Figure $1 \mathrm{c}$ shows the changes in total cholesterol, LDL cholesterol and total/HDL ratio according to changes in FM. Total cholesterol decreased by $-0.6 \pm 1.0 \mathrm{mmol} / \mathrm{l}$ in the $\mathrm{FM} \downarrow$ group $(P<0.001), \quad-0.3 \pm 1.2 \mathrm{mmol} / \mathrm{l}$ in the $\mathrm{FM}=\operatorname{group}(P<0.001)$ and $-0.2 \pm 1.0 \mathrm{mmol} / \mathrm{l}$ in the FM $\uparrow$ group $(P<0.05)$, while the ratio decreased by $-0.5 \pm 1.0 \quad(P<0.001), \quad-0.51 \pm 1.8 \quad(P<0.01)$, $-0.3 \pm 1.1 \quad(P<0.01)$ respectively. Multivariate analysis demonstrated that the magnitude of the loss of FM was a significant predictor of the decrease in total 
serum cholesterol. The change in HDL cholesterol was not significant and the increase in triglycerides was limited and only significant in the FM $\downarrow$ and FM $\uparrow$ groups $(P<0.05)$.

QoL-AGHDA scores in the three groups in relation to the variables of obesity are shown in Fig. 2. The improvement in QoL from baseline was highly significant in each subgroup $(P<0.001)$. The most pronounced improvement in QoL-AGHDA score was found in the BMI $\downarrow$, WG $\downarrow$ and FM $\downarrow$ groups. Nevertheless, multivariate analysis revealed a significant difference only for the comparison between BMI $\downarrow$ and $\mathrm{BMI}=$ groups.

\section{Discussion}

This study confirms the well-known unfavourable lipid profile and poor QoL in GHD patients, but also emphasizes the additional adverse effect of higher BMI and WG. More importantly, it demonstrates that the improvement in lipid metabolism and QoL during GH replacement therapy is independent of changes in indicators of obesity such as BMI, WG and FM.

It should be underlined that the arbitrary construction of the BMI and WG groups is responsible for some significantly different features between the groups. The BMI $<25$ and the WG-normal groups diverge from the other groups in the percentage of childhood-onset patients and hence an earlier mean age at diagnosis and at initiation of $\mathrm{GH}$ replacement therapy than in those with adult-onset GHD, but also, as reported in other studies (27), a significantly lower baseline IGF-I concentration. The BMI $=25-30$ and BMI $>30$ groups were similar populations, except for a difference in gender distribution. While the overall cohort of GHD

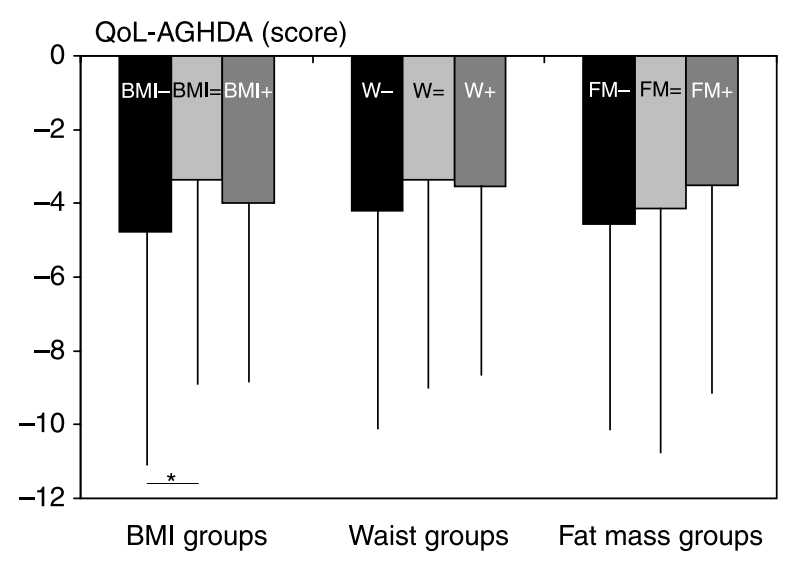

Figure 2 Changes in quality of life measured by the Quality of Life Assessment of GHD in Adults (QoL-AGHDA) in subjects with growth hormone deficiency (GHD) classified according to changes in body mass index (BMI), waist girth (WG) and fat mass (FM) after 1 year of growth hormone replacement. Values are means \pm S.D. ${ }^{*} P<0.05$. patients were characterized by an elevated BMI corresponding to a definition of overweight, BMI in females tended to have a biphasic distribution - either a normal BMI or obese, whereas males were more frequently overweight. The possibility that these dissimilarities may account for differences in lipid metabolism and QoL should be taken into account. Nevertheless, two important similarities exist between the groups making them homogeneous in the analysis of the lipid and QoL data. Firstly, although lower for the BMI $<25$ and the WG-normal groups, the mean ages ranging between 40 and 47 years excludes age as a major determinant in the interpretation of the lipid measurements. Indeed, it was recently demonstrated that the maximal deterioration of the lipid profile in GHD patients is achieved at the age of 40 without further worsening afterwards but remaining adverse throughout life (6). Secondly, as the duration of GHD without GH replacement ranged between 9 and 11 years in all groups, it is highly unlikely that this parameter would affect the outcome in terms of lipids and QoL.

The lipid profile in the different BMI and WG groups showed some distinct baseline characteristics. The classical finding of elevated total cholesterol and LDL cholesterol in comparison with recommended target values of $5.2 \mathrm{mmol} / \mathrm{l}$ and $3.4 \mathrm{mmol} / \mathrm{l}$ respectively was seen in all groups. This indicated GHD as a dominant cause for the adverse cholesterol profile as the changes were independent of BMI and WG. This could be due to inadequate LDL receptor activity (28). The HDL cholesterol concentration, on the other hand, varied significantly among the BMI and WG groups. The higher HDL cholesterol level in the BMI $<25$ group could be explained by the higher percentage of females in this group. Thus, the increase in BMI was probably the main factor that adversely influenced HDL cholesterol. Consequently, BMI and WG had an important impact on the total/HDL cholesterol ratio, with the target value of 4.5 progressively exceeded by increasing BMI and WG. Also, the increased triglycerides were clearly dependent on BMI and WG in such a way that a concentration below the target value of $1.7 \mathrm{mmol} / \mathrm{l}$ was found only in the BMI $<25$ group. The data in the FM group mirrored the adverse lipid findings of any unselected cohort of GHD patients reported in the literature. The present data thus disclose a profound impact of BMI and WG upon the lipid profile of GHD patients as has been reported in individuals without GHD (20). GHD patients are, however, more seriously affected through the adverse effect of GHD on LDLcholesterol.

The QoL-AGHDA score confirmed the poor QoL in the GHD group as a whole, but obese patients and patients with an increased WG had significantly worse scores, suggesting that, in addition to GHD, obesity per se contributes to the impairment of QoL.

The recognized effect of GH replacement on BMI, WG and FM was seen in the whole study population. No 
changes in BMI were found after 1 year and although the BMI > 30 group showed a significant decrease in BMI, it is probably too small to be of any clinical relevance. On the other hand, a significant improvement in WG and FM occurred regardless of the BMI group studied, implying that BMI need not be taken into account when deciding whether to start GH replacement therapy or not. A similar picture was found for the WG-normal and WG-abnormal groups, confirming that $\mathrm{GH}$ replacement is effective in decreasing $\mathrm{WG}$ and reducing FM independent of the initial composition, while BMI was not influenced.

The same conclusion can be drawn concerning the effect of GH replacement on the lipid profile and QoL. Regardless of BMI, WG and FM status, significant decreases in total cholesterol, LDL cholesterol and total/HDL ratio were seen without any changes in HDL cholesterol. On the other hand, a limited increase in triglycerides was found, which could be explained by a decrease in insulin sensitivity or increased availability of free fatty acids during $\mathrm{GH}$ replacement resulting in increased hepatic very LDL secretion. The favourable effects of $\mathrm{GH}$ replacement were independent of the parameters of obesity and can thus be considered as self-determining. This finding supports previous findings from the literature $(29,30)$, although it conflicts with some other data $(23,24)$. Moreover, administration of $\mathrm{GH}$ changed all studied variables in a similar way in nearly all groups, suggesting that the favourable response to $\mathrm{GH}$ was maintained independent of the presence or degree of obesity. The improvement of QoL during GH replacement was highly significant in all groups and again not determined by obesity. All these data strongly suggest that in subjects with GHD the beneficial effects of GH replacement on WG, FM, lipid profile and QoL are independent of the individual's baseline obesity status, whether expressed as BMI, WG or body composition measured by BIA.

In conclusion, the improvements in total cholesterol, LDL cholesterol and total/HDL ratio induced by $\mathrm{GH}$ replacement therapy were independent of changes in obesity variables. The decrease in lipid profile was most prominent when it was accompanied by a decrease in BMI, WG or FM, although without statistical significance. Importantly, the favourable effect of GH was present even in patients with increased BMI, WG and FM, indicating that the improvement was unrelated to changes in obesity parameters. Adaptation of lifestyle to reach a more balanced body composition offers an additional advantage, but $\mathrm{GH}$ replacement is the main determinant of lipid control. Improvement in QoL was another distinct effect of GH replacement and was seen in all BMI, WG and FM groups irrespective of changes within the groups during this treatment. This finding suggests that the reduced QoL in GHD was diseasespecific and responded well to $\mathrm{GH}$ replacement.

\section{Declaration of interest}

The authors declare that there is no conflict of interest that would prejudice the impartiality of this scientific work.

\section{Funding}

Editorial support was provided by Rx Communication Ltd and was funded by Pfizer Health AB.

\section{Acknowledgements}

The authors thank the KIMS investigators worldwide who provided the data on their patients and the colleagues working at Medical Outcomes in Sollentuna, Sweden. The KIMS database is sponsored by Pfizer.

\section{References}

1 Rosén T \& Bengtsson B-Å. Premature mortality due to cardiovascular disease in hypopituitarism. Lancet $1990336285-288$.

2 Bülow B, Hagmar L, Mikoczy Z, Nordström CH \& Erfurth EM. Increased cerebrovascular mortality in patients with hypopituitarism. Journal of Clinical Endocrinology and Metabolism $1997 \mathbf{4 6}$ 75-81.

3 Svensson J, Bengtsson B-Å, Rosén T, Odén A \& Johannsson G. Malignant disease and cardiovascular morbidity in hypopituitary adults with or without growth hormone replacement therapy. Journal of Clinical Endocrinology and Metabolism $2004 \mathbf{8 9}$ 3306-3312.

4 Beshyah SA \& Johnston D. Cardiovascular disease and risk factors in adults with hypopituitarism. Clinical Endocrinology $1999 \mathbf{5 0}$ $1-15$.

5 Abdu TA, Neary R, Elhadd TA, Akber M \& Clayton RN. Coronary risk in growth hormone deficient hypopituitary adults: increased predicted risk is due largely to lipid profile abnormalities. Clinical Endocrinology 200155 209-216.

6 Abs R, Feldt-Rasmussen U, Mattsson AF, Monson JP, Bengtsson B-Å, Góth MI, Wilton P \& Koltowska-Häggström M. Determinants of cardiovascular risk in 2589 hypopituitary growth hormone-deficient adults. European Journal of Endocrinology 2006155 79-90.

7 Sesmilo G, Biller BM, Llevadot J, Hayden D, Hanson G, Rifai N \& Klibanski A. Effects of growth hormone administration on inflammatory and other cardiovascular risk markers in men with growth hormone deficiency. A randomized, controlled clinical trial. Annals of Internal Medicine 2000133 111-122.

8 Jørgensen JO, Pedersen SA, Thuesen L, Jørgensen J, IngemannHansen T, Skakkebaek NE \& Christiansen JS. Beneficial effects of growth hormone treatment in GH-deficient adults. Lancet 19891 1221-1225.

9 Libber SM, Plotnick LP, Johanson AJ, Blizzard RM, Kwiterovich PO \& Migeon CJ. Long-term follow-up of hypopituitary patients treated with human growth hormone. Medicine 199069 46-55.

10 Abs R, Bengtsson B-Å, Hernberg-Stå E, Monson JP, Tauber J-P, Wilton $\mathrm{P} \&$ Wüster $\mathrm{C}$. Growth hormone replacement in hypopituitary adults. Demographic, clinical, and dosing characteristics in 1034 patients. Clinical Endocrinology $1999 \mathbf{5 0}$ 703-713.

11 Beshyah SA, Freemantle C, Thomas E, Rutherford O, Page B, Murphy M \& Johnston DG. Abnormal body composition and reduced bone mass in growth hormone deficient hypopituitary adults. Clinical Endocrinology 199542 179-189.

12 Mersebach H \& Feldt-Rasmussen U. Growth hormone and body composition. Growth hormone deficiency in adults. In Frontiers of Hormonal Research, vol 33, pp 185-195. Eds JOL Jørgensen \& JS Christiaensen. Basel: Karger, 2005. 
13 Cuneo RC, Salomon F, Watts GF, Hesp R \& Sonksen PH. Growth hormone treatment improves serum lipids and lipoproteins in adults with growth hormone deficiency. Metabolism $1993 \mathbf{4 2}$ 1519-1523.

14 Salomon F, Cuneo RC, Hesp R \& Sonksen PH. The effects of treatment with recombinant human growth hormone on body composition and metabolism in adults with growth hormone deficiency. New England Journal of Medicine 1989321 1797-1803.

15 Boguszewski CL, Meister LH, Zaninelli DC \& Radominski RB. One year of GH replacement therapy with a fixed low-dose regimen improves body composition, bone mineral density and lipid profile of GH-deficient adults. European Journal of Endocrinology 2005152 $67-75$.

16 McKenna SP, Doward LC, Alonso J, Kohlmann T, Niero M, Prieto L \& Wíren L. The QoL-AGHDA: an instrument for the assessment of quality of life in adults with growth hormone deficiency. Quality of Life Research 19998 373-383.

17 Herschbach P, Henrich G, Strasburger CJ, Feldmeier H, Marín F, Attanasio AM \& Blum WF. Development and psychometric properties of a disease-specific quality of life questionnaire for adult patients with growth hormone deficiency. European Journal of Endocrinology 2001145 255-265.

18 Rosilio M, Blum WF, Edwards DJ, Berthezene F, Shavrikova EP, Valle D, Lamberts SWJ, Erfurth EM, Webb SM, Ross RJ, Chihara K, Henrich G, Herschbach P \& Attanasio AF. Long-term improvement of quality of life during growth hormone $(\mathrm{GH})$ replacement therapy in adults with GH deficiency, as measured by questions on life satisfaction-hypopituitarism (QLS-H). Journal of Clinical Endocrinology and Metabolism 200489 1684-1693.

19 Koltowska-Häggström M, Mattsson AF, Monson JP, Kind P, Badia X, Casanueva FF, Busschbach J, Koppeschaar HPF \& Johannsson G. Does long-term growth hormone replacement therapy in hypopituitary adults with growth-hormone deficiency normalise quality of life? European Journal of Endocrinology 2006 155 109-119.

20 Brown CD, Higgins M, Donato KA, Rohde FC, Garrison R, Obarzanek E, Ernst ND \& Horan M. Body mass index and the prevalence of hypertension and dyslipidemia. Obesity Research 20008 605-619.

21 Douketis JD \& Sharma AM. Obesity and cardiovascular disease: pathogenic mechanisms and potential benefits of weight reduction. Seminars in Vascular Medicine 20055 25-33.

22 Dixon JB, Dixon ME \& O'Brien PE. Quality of life after lap-band placement: influence of time, weight loss, and comorbidities. Obesity Research 2001 9 713-721.
23 Hoffman AR, Kuntze JE, Baptista J, Maum HB, Baumann GP, Biller BM, Clark RV, Cook D, Inzucchi SE, Kleinberg D, Klibanski A, Phil LS, Ridgway EC, Robbins RJ, Schlechte J, Sharma M, Thorner MO \& Vance ML. Growth hormone replacement therapy in adult-onset growth hormone deficiency: effects on body composition in men and women in a double-blind, randomised, placebo-controlled trial. Journal of Clinical Endocrinology and Metabolism $2004892048-2056$.

24 Abrahamsen B, Nielsen TL, Hangaard J, Gregersen G, Vahl N, Korsholm L, Hansen TB, Andersen M \& Hagen C. Dose-, IGF-I- and sex-dependent changes in lipid profile and body composition during GH replacement therapy in adult onset $\mathrm{GH}$ deficiency. European Journal of Endocrinology 2004150 671-679.

25 Gutiérrez LP, Kołtowska-Häggström M, Jönsson PJ, Mattsson AF, Svensson D, Westberg B \& Luger A. Registries as a tool in evidencebased medicine: example of KIMS (Pfizer International Metabolic Database). Pharmacoepidemiology and Drug Safety 200868 122-129.

26 Friedewald WT, Levy RI \& Fredickson DS. Estimation of the concentration of low-density lipoprotein cholesterol in plasma without use of the preparative ultracentrifuge. Clinical Chemistry 197218 499-502.

27 Lissett C, Jonsson P, Monson JP \& Shalet SM. Determinants of IGF-I status in a large cohort of growth-hormone deficient (GHD) subjects: the role of timing of onset of GHD. Clinical Endocrinology $200359773-778$.

28 Russel-Jones DL, Watts GF, Weissberger A, Naoumova RP, Myers J, Thompson GR \& Sonksen PH. The effects of growth hormone replacement on serum lipids, lipoproteins, apolipoproteins and cholesterol precursors in adult growth hormone deficient patients. Clinical Endocrinology $1994 \mathbf{4 1}$ 345-350.

29 Vahl N, Jorgensen JO, Hansen TB, Klausen IB, Jurik AG, Hagen C \& Christiansen JS. The favorable effects of growth hormone substitution on hypercholesterolaemia in GH-deficient adults are not associated with concomitant reductions in adiposity. A 12 month placebo-controlled study. International Journal of Obesity and Related Metabolic Disorders 199822 529-536.

30 Hana V, Silha JV, Justova V, Lacinova Z, Stepan JJ \& Murphy LJ. The effects of GH replacement in adult GH-deficient patients: changes in body composition without concomitant changes in adipokines and insulin resistance. Clinical Endocrinology $200460442-450$.

Received 27 July 2008

Accepted 1 August 2008 